\title{
Os livros
}

“Segurança em Laboratórios Químicos”, Maria João Baptista, Ed. da Universidade Nova de Lisboa, 1979, 111 págs., $180 \$ 00$.

Escrever um livro sobre este tema num País em que o "desenrasca", aliás superiormente assistido pela "falta de verbas", é um estado de espírito pode parecer um "clamor no deserto".

$\mathrm{Na}$ realidade poucos assuntos assumiram menos importância nas mentes planeadoras das unidades laboratoriais escolares e de investigação deste País (daqui saúdo as excepçð̃es) do que a Segurança.

O "rosário de azares" vindos a público têm no entanto resultado num aumento da consciencialização dos utentes dos laboratórios químicos para os problemas de Segurança, passo fundamental para se conseguir a modificação do actual estado de coisas. É neste contexto que julgo muito oportuna a divulgação deste livro junto de todos os que no, ou em torno do, laboratório desenvolvem a sua actividade (Professores, Estudantes, Investigadores) e que não assumam de modo irresponsável o slogan "o perigo é a minha profissão".

Dos diversos problemas tratados ao longo do texto, 111 páginas muito concisas e claras, cabe salientar a atenção dada às infra-estruturas de segurança, i.e., o conjunto de estruturas, pessoas e meios cujo funcionamento assegura a diminuição permanente do nível de risco no trabalho. São disso exemplos entre outros os capítulos sobre Responsabilidade e Planeamento de Segurança, Armazenagem de Reagentes, Regras Gerais de Segurança, cursos sobre Segurança e Laboratórios Químicos, Prevenção de Incêndios. Trata-se do tipo de assuntos sobre os quais as pessoas "têm ideias"' mas cuja passagem à prática, de forma metódica, coerente e organizada não é geralmente feita. É ideia patente da autora, que subscrevo inteiramente, que é numa política de "Profilaxia do acidente" que se baseará o sucesso de qualquer esquema de segurança.

Para além destes aspectos oferecem-se vários capítulos com informação detalhada sobre questōes concretas e usuais nos laboratórios, funcionando a nível de manual em assuntos como Técnicas Laboratoriais, Primeiros Socorros, Armazenamento e Cuidados com Reagentes Especiais (explosivos, inflamáveis, corrosivos, incompatíveis, etc.), Combate a Incêndios, etc. Uma divulgação destes capítulos aos estudantes, quando devidamente integrada nos seus trabalhos práticos, será extremamente útil para a sua formação ajudando-os a ajuizar do porquê e da importância de certos procedimentos de segurança que lhes são (ou deveriam ser) exigidos.

De facto, tanto o destemor irresponsável como o temor paralisante são atitudes a evitar na prática laboratorial.
O livro dispōe ainda de uma secção (impressa em folhas azuis para mais rápida identificação) com informaçōes sobre perigos e cuidados a ter com cerca'de 90 compostos e/ou tipos de compostos mais comuns nos laboratórios, ordenados por ordem alfabética.

É um tipo de informação extremamente útil especialmente em laboratórios ou escolas cujas bibliotecas não dispõem dos manuais muito completos (normalmente caros) sobre propriedades de compostos, em particular, as referentes a questões de segurança (inflamabilidade, toxicidade, etc.).

Cumpre destacar ainda a abundante bibliografia (101 referências) de muita utilidade para o leitor mais interessado e/ou envolvido em problemas mais específicos.

Carlos Romão

Dep. de Engenharia Química, IST

\section{"Hazards in the Chemical Laboratory", editor L. Bretherick, Royal Society of Chemistry (3. ${ }^{a}$ edição), 1981, 592 págs., $£ 15.00$.}

Hazards in the Chemical Laboratory é uma das mais autorizadas e completas fontes de informação no campo da segurança em laboratórios químicos. Trata-se da 3. ${ }^{\text {a }}$ edição, editada por L. Bretherick - um dos maiores especialistas mundiais em normas e critérios de segurança - e é um livro essencial em qualquer laboratório onde se manuseie equipamento e produtos químicos.

Em relação à 2. ${ }^{\text {a }}$ edição (1977), inclui uma nova secção intitulada Cuidados de Saúde e Primeiros Socorros que trata de produtos químicos carcinogénicos e mutagénicos, controles biológicos para produtos químicos especificos, medidas preventivas, primeiros socorros, produtos químicos associados com a indução do cancro e ainda indicações sobre centros europeus de informação sobre venenos e inspecção de trabalho e autoridades de saúde ocupacional na Europa.

As duas secçōes sobre os perigos associados aos produtos químicos foram amplamente revistas e aumentadas de modo a incluirem o crescente conhecimento sobre o assunto - em 1974 a lista de substâncias tóxicas incluia 13000 compostos e em 1978 esse número passou para 34000 . Assim, a secção sobre produtos químicos reactivos aborda entre outras aspectos os efeitos de temperatura e pressão, factores físico-químicos, estrutura e reactividade, compostos redox, pirofosfóricos, peroxidáveis e que reagem com a água, misturas reactivas perigosas, produtos químicos incompatíveis e riscos potenciais de armazenagem; o capítulo Produtos Químicos Perigosos inclui uma secção organizada alfabeticamente 
e constituida por monografias sobre os produtos químicos mais comuns (propriedades, advertências da CEE, recomendaçð̃es, efeitos tóxicos, reacçð̄es perigosas, primeiros socorros e tratamento, riscos de incêndio, processos de eliminação em caso de derrame) e ainda notas curtas sobre os perigos e reacçðes de algumas centenas de outros produtos menos comuns.

As outras secçōes do livro cobrem aspectos de política e planeamento da segurança (serviços e equipamento, instalações, iluminação, ventilação e chaminés, mobiliário e bancadas, equipamento de vácuo e de pressão, material de laboratório - manuseamento, armazenagem e eliminação - cilindros de gases, remoção de lixo, etc.); protecção contra o fogo (natureza e origem dos riscos, acções de emergência, tipo de fogo e agentes de extinção mais apropriados); precauções contra as radiaçð̃es (tipos de radiação, efeitos, dose limite, precauçð̄es no manuseamento de fontes radioactivas, aparelhos de medida, precauções contra radiações não ionizantes, ultravioleta, infravermelha, laser, ultra-sons e microondas) e ainda aspectos toxicológicos dos produtos químicos (leis básicas da toxicologia, cinética e metabolismo: absorção e distribuição, metabolismo, excreção, dose e efeito, limites permissíveis de exposição, exposição e forma de absorção, consequências da exposição a matérias tóxicas - trato respiratório e pulmōes, pele e olhos, trato gastrointestinal e figado, sistema cardiovascular, ossos e músculos). Contém ainda uma secção sobre legislação que embora não aplicável poderá servir como orientação neste capítulo.

Os membros da Royal Society of Chemistry têm um desconto na aquisição deste livro; cada cópia contém um vale de $5 \underline{f}$ que pode ser usado como parte do pagamento da assinatura do "Laboratory Hazards Bulletin" publicado mensalmente pela R.S.C.

\section{"Health and Safety in the Chemical} Laboratory - Where Do We Go From Here?"' Publicação especial n. ${ }^{\circ} 15$ da Royal Society of Chemistry, 198 págs., £ 16.50, (1984).

O livro de viii + 198 páginas compreende um compilação de um simpósio internacional, organizado pela Royal Society of Chemistry sob os auspícios do Grupo de Trabalhos Profissionais da Federação Europeia de Sociedades de Química que decorreu na Universidade de Lancaster, Reino Unido, de 12 a 13 de Abril de 1983. A maior parte do volume consta de 14 comunicações apresentadas e da discussão subsequente, mas nas páginas finais estão as recomendações saidas do simpósio, a saber:

1. Há uma necessidade imediata e contínua de que as sociedades de Química:

- façam com que o grande público fique mais a par de que os químicos profissionais estão activamente envolvidos em fazer com que a segurança na química aumente; - contraponham e desencoragem comentários de meios de comunicação adversos relativos à saúde e segurança em Química.

2. Há uma necessidade a longo prazo de que as sociedades de Química participem no desenvolvimento de:

- harmonização internacional de indicações voluntárias sobre saúde e segurança;

- padronização internacional de definições de aciden- tes e de estatísticas de acidentes juntamente com uma tendência coordenada para obter estatísticas detalhadas sobre acidentes e ocorrências perigosas;

- padronização nacional (pelos governos de base mandatária ou por organizaçðes independentes de base consultiva) da avaliação da eficácia do custo de medidas de controlo relativas a saúde e segurança;

- procedimentos comuns e padrões mínimos (possivel: mente através de comités especiais de protocolo) para saúde e segurança no local de trabalho;

- procedimentos comuns para a identificação, relato e incidência de problemas de saúde derivados de doenças relacionadas com o trabalho;

- programas, com parte prática, em saúde e segurança (possivelmente levados a cabo por organismos profissionais) que possam ser utilizados em pequenos negócios. 3. Há uma necessidade a longo prazo de:

- uma definição aceite internacionalmente de carcinogénio, a ser estabelecida;

- estudos de morbilidade e mortalidade a serem conduzidos por trabalhadores profissionais que não sejam químicos e entre trabalhadores técnicos e manuais; e para sindicatos conduzirem esses éstudos entre os seus membros;

- prémios reduzidos a serem cobrados por companhias de seguro a organizações com bons registos de saúde e segurança;

- maior colaboração em saúde e segurança entre organismos profissionais nos campos da química e toxicologia;

- maior tomada de consciência da toxicologia a ser incluida no treino de químicos.

Traduzido de

Chemistry Internacional 7(3), 23 (1985) por Mariana Pereira

\section{"Fontes de Informação em Ciência e Tecnologia: Química e Tecnologia Química", Ana Maria R. Correia, Maria João M. Curto, Edição do Cedintec, Lisboa (1985), $400 \$ 00$.}

Uma obra como a que nos é agora apresentada é extremamente útil por dois motivos diferentes: por um lado, porque lista e descreve as principais fontes de informação para a Química e a Tecnologia Química; por outro lado porque ajuda o leitor a delinear uma estratégia de utilização dessas mesmas fontes, imprescindivel, mais do que nunca, na pesquisa automatizada de bases de dados.

A oportunidade da obra, produto de autoras com larga e variada experiência no campo, está bem patente pois traduz, ela própria, uma nova dinâmica da investigação química e da exploração industrial que ora se regista. Daí que pensemos que ela se tornará num elemento indispensável não só de qualquer biblioteca, mas também uma valiosa obra de consulta do investigador ou do técnico, do professor de química e do próprio aluno.

Do prefácio à obra por

A. M. Lobo

Rodrigues de Magalhães 
"Primórdios da Ciência Química em Portugal”, A.M. Amorim da Costa, Lisboa, Instituto de Cultura e Língua
Portuguesa (1984), 200\$00

A obra Primórdios da Ciência Química em Portugal de Amorim da Costa, publicada ultimamente pela Biblioteca Breve, se outros méritos não tivesse, valeria pela chamada de atenção que constitui, no que respeita à quase inexistência de obras recentes sobre a História da Química em Portugal.

O trabalho já mencionado, de cunho essencialmente divulgador, encontra-se estruturado, após breve apontamento sobre a Iatroquímica, de modo a dar-nos conta da importância da Reforma Pombalina da Universidade de Coimbra em favor da institucionalização de uma prática química mais ou menos sistemática e, posteriormente, do seu estatuto como ciência experimental.

Não obstante, a grande qualidade do trabalho apresentado pelo Prof. Doutor Amorim da Costa, a sua enorme utilidade e as pistas fornecidas para posteriores investigações, atrever-me-ei, mesmo assim, a levantar algumas questð̃es suscitadas aquando da sua leitura.

Estas questð̃es, longe de pretenderem constituir uma crítica, deverão ser entendidas como problemas de ordem marcadamente metodológica que se colocaram a quem ensaia os primeiros passos no ofício.

Assim, e como ponto de partida citarei, por exemplo, o que é dito acerca de Thomé Rodrigues Sobral, nomeado, em 1791, lente de Química e Metalurgia da Universidade de Coimbra.

"Como refere o Prof. Simões de Carvalho, os serviços prestados por Rodrigues Sobral ao ensino da Química e ao seu País em épocas memoráveis foram de tal ordem que lhe valeram a honrosa denominação de Chaptal Português. Fizeram-lhe essa justiça os sábios escritores Link e Balbi, por comparação com Jean Baptiste Chaptal (1756-1832), o médico francês que se notabilizou na química industrial, e cujo Ensaio sobre o aperfeiçoamento das Artes Químicas em França (editado em 1800) é das mais importantes marcas no desenvolvimento da química aplicada. Todavia a denominação de Guiton Português ficar-lhe-ia de igual modo bem. Como o quimico de Dijon, barão de Morveau, que tantas vezes cita com grande admiração e de cujo Tratado das Afinidades Químicas é tradutor para português, como referimos já, Rodrigues Sobral foi o grande impulsionador em Portugal, dos métodos da desinfecção pública..." (pág. 75).

Se acrescentar a este trecho a citação que o autor faz de Andrade de Gouveia (cfr., ANDRADE DE GOUVEIA, A. J., Químico esclarecido: Vicente de Seabra (1764-1804), in Memórias da Academia das Ciências de Lisboa, vol. XXI $(976 / 77))$ a propósito dos Elementos de Chimica (1788-1790) de Vicente Coelho de Seabra: "adopta a Química do oxigénio com consideraçð̃es críticas, mas sem restriçōes de fundo. Apresenta conhecimento exacto e fundamentado, às vezes por experiências próprias, de problemas químicos da época: composição do ar, reconhecimento de substâncias elementares e suas propriedades..." (pág. 62) poderemos constatar o seguinte: o sentido marcadamente eclético da sua actividade científica e a forma como ambos veicularam teorias e práticas importadas do estrangeiro. Nota-se assim, a preocupação em ensinar, aplicar e di- vulgar a novidade vinda do exterior, havendo uma enorme permeabilidade que encerra em si, frequentemente, ambivalências por vezes, contraditórias. A ilustrá-las veja-se o que é afirmado na página 76: "É pois possível que em 1798 ele (Thomé Rodrigues Sobral) fosse ainda defensor de se não ensinar química por outro compêndio que não fosse o de Scopoli $\left({ }^{a}\right)$, pelo muito que estimava esse manual embora, certamente o adoptasse com várias reservas pois só assim se compreende o testemunho de Link que se refere exactamente a essa época: il enseigne la Chimie d'après les nouveaux principes antiphlogistiques."

Pese embora o facto de, nesta altura, ainda não existir um compêndio de Química de autoria portuguesa e, Thomé Rodrigues Sobral ter um em preparação, esta situação enquadra-se num contexto geral permeável ao aparecimento de casos que, muito genericamente, se poderão de algum modo tipificar da seguinte maneira: - inexistência de correntes de pensamento científico com contornos bem definidos, com uma real e significativa correspondência na prática científica; - emergência, por vezes meteórica, de "grandes figuras" isoladas que, frequentemente, emigram ou são a isso forçadas, desinserindo-se assim do contexto português; - personalidades vindas do exterior tidas por detentoras da novidade que se pretende implantar; - aparecimento de figuras que, sem apresentarem trabalhos originais ou inovadores, no sentido de protagonizarem revoluçōes científicas, atingem projecção internamente quer como difusoras do novo, quer porque aplicam a sua ciência em sectores que beneficiam a comunidade incarnando, por vezes, ideais e aspirações. Porque a História das Ciências tem um objectivo concreto que é a ciência que se faz com todas as suas condicionantes e particularidades, a justa medida daquilo que se analisa não pode ser escamoteada.

No entanto, o que é mais comum é historiar-se a ciência, em Portugal, caindo em exageros de análise com destaque para: - valorização das personalidades científicas a tal ponto que se transforma a História das Ciências numa saga de "grandes vultos" atribuindo-lhes muitas vezes características de antecipação cientifica, nem sempre exactas; - descrição das personalidades por meio de comparaçōes, havendo injustiça para ambas as partes, sendo disso exemplo epítetos como os já mencionados do tipo "Chantal Português" ou "Guiton (sic) Português; - completa demissão de se fazer a História da Ciência portuguesa, por considerá-la incaracterística e desinteressante do ponto de vista da inovação conceptual.

Posto isto, qual será o lugar da investigação histórica sobre a produção científica portuguesa? Qual a metodologia mais adequada às características que ela apresenta? Dever-se-á apontar para uma história assente em "figuras" ou fundada em estratos pluridisciplinares?

Sem ter a pretensão de querer dar uma resposta termino por dizer que a História das Ciências em Portugal representa, na verdade, um desafio.

Este desafio coloca-se a dois niveis distintos: o primeiro implica uma procura metodológica capaz de determinar, com justeza, o lugar das ciências nos diversos contextos históricos da cultura portuguesa, sem preconceitos de qualquer espécie; o segundo, consiste numa busca daquilo em que, de facto, a ciência portuguesa poderá ser original e que eventualmente, terá que

(a) Scopoli, Quimico defensor da Teoria do Flogisto. 
passar pelo levantamento do papel das ciências face aos problemas postos pelo mundo dos trópicos que, mercê talvez dum passado colonizador recente suscita naturalmente, certos receios de conservadorismo e problemas de consciência.

Porque muito pouco está feito e porque muito há para fazer, é de saudar o aparecimento da obra Primórdios da Ciência Química em Portugal cuja leitura é indispensável, pois representa um importante ponto de partida.

Ana Maria Carneiro

Departamento de Química, FCUL

\section{“'O Universo Inteligente”, Fred Hoyle, Editorial Presença (1985), $1.600 \$ 00$}

Grande foi a nossa estupefacção ao lermos, há alguns anos, o título duma comunicação de F. Hoyle e C. Wickramasinghe em que era anunciada a obtenção de evidência, por espectroscopia de infra-vermelhos, da presença de proteínas (ou péptidos) algures no espaço sideral. Depois de lermos o texto concluímos que os autores tinham afinal cometido o erro que nós procuramos que os nossos estudantes não cometam e que nos fazem dizer: "a ausência dum pico espectral poderá ser prova da ausência dum dado composto, mas a presença dum pico por si só nada prova quanto à presença seja do que for"'. Depois de termos lido este livro de Hoyle, ficámos com a impressão de que se tivesse alguma vez argumentado, com a mesma ingenuidade, que encontrara, por infra-vermelhos, evidência de que existem vírus já feitos e prontos para nos atacarem de gripe no próximo inverno, o erro científico talvez fosse da mesma ordem de grandeza, mas por certo o efeito sobre o leitor leigo nestes assuntos, esse valeria a pena.

No primeiro capitulo deste seu livro, Hoyle rejeita liminarmente todo o trabalho de algumas centenas de químicos que durante os últimos trinta anos têm vindo a demonstrar que existe realmente uma evolução química prebiótica que é de resto evidente nos meteroritos e outros corpos celestes que têm sido observados durante os últimos anos. Mas para isso usa dados da própria Química que, mais uma vez, estão infelizmente errados. É o exemplo sonante mas ingénuo da banheira cheia de produtos químicos à espera de que se forme um dos 2000 enzimas conhecidos (sem banheira e com muito menos produtos químicos obtêm-se hoje, com toda a facilidade, de entre os milhoes de compostos orgânicos conhecidos, essencialmente e quase apenas os monómeros, ou os seus percursores, dos polímeros biológicos). É o exemplo de grande efeito da comparação da probabilidade de resolução do cubo de Rubik com a probabilidade da produção de péptidos bio-activos (o autor parece ignorar que os aminoácidos não se comportam quimicamente todos da mesma maneira e ignora que em experiências de simulação prebióticas os aminoácidos de Miller originam proteinóides com actividade pré-enzimática); este é um exemplo da aplicação do cálculo de probabilidades a dados viciados. Mas Hoyle não gasta muito tempo com a Quimica.

No segundo capítulo comenta Darwin e rejeita liminarmente a evolução biológica neo-Darwinista (micro-evolução), usando argumentos da Genética Molecular. Certamente estes argumentos são de peso, mas não acreditamos que qualquer geneticista molecular, mesmo prémio Nobel, como Crick, interprete os seus re- sultados com a mesma ligeireza com que Hoyle o faz - de resto esquece que também há um prémio Nobel a estudar a evolução química para a vida. Depois entra rapidamente no terceiro capítulo para nos transmitir a grande mensagem do seu livro: a vida veio do Espaço. Quando os canais de Marte foram descobertos na primeira década deste século, começou a falar-se de marcianos e de vida fora da Terra; foi então que Arrhenius propôs a hipótese da panspermia que Hoyle retomou substituindo esporos por vírus (também aqui o autor não é original, pois já nos anos vinte se pensou que a vida surgiu dos cristais, os vírus cristalinos). No entanto, ensinaram-nos que os vírus só podem reproduzir-se e dar origem a nova vida parasitando outras espécies; assim, não entendemos como poderão ter germinado e produzido vida na Terra antes de cá haver vida. À medida que avançámos na leitura, a nossa curiosidade foi crescendo, pois gostaríamos de saber como teriam surgido no Universo os primeiros vírus, mas afinal chegámos ao fim sem que o autor desvendasse este mistério que continua de pé. Mas começamos a afastar-nos da Química e não quereríamos seguir o caminho de Hoyle, argumentando em terrenos que não são da nossa especialidade.

Há quase vinte anos deliciámo-nos a ler os livros de Erich Von Daniken em que o autor re-interpretava dados arqueológicos para consubstanciar a sua teoria de que a Terra foi visitada por extra-terrestres em tempos pré-históricos. Von Daniken criava a imagem dum fanático utilizando a ciência para construir uma anti-ciência servindo a sua religião de extra-terrestres. Depois surgiram outros autores ainda mais fanáticos (ou menos escrupulosos) e este tipo de literatura, que se tinha popularizado, caiu em descrédito. Ler Hoyle deliciou-nos tanto como ler Von Daniken, pelas suas ideias igualmente originais e até pela sua própria anti-ciência. Admirtamos Hoyle pela sua coragem e perseverança e respeitámo-lo pelo reconhecimento científico que a sua actividade como astrónomo tem recebido; além disso diverte-nos com as suas diabruras no domínio da Química, que de resto é bem evidente ser ciência de que não gosta (pois se gostasse da Química talvez fosse um fanático da teoria da evolução química para a vida). Assim recomendamos vivamente a leitura de "O Universo Inteligente" nas suas férias; leve também alguns dos livros heréticos de Von Daniken ou seus sucessores, alguns romances policiais e também alguns livros de ovniologia ou ficção científica; os últimos poderão ser do próprio Sir Fred Hoyle de que também é autor conhecido.

Hernani Maia
Universidade do Minho

\section{“A Criação", P. W. Atkins, Editorial Presença (1985),}

$850 \$ 00$

«Remontamos agora para lá do momento da criação, quando não havia tempo e onde năo havia espaço. Deste nada nasceu o espaço-tempo, e com o espaço-tempo nasceram as coisas. Na devida altura surgiu também a consciência, e o universo, inicialmente inexistente, cresceu ciente e si próprion.

A obra de Peter Atkins que é objecto deste comentário é muito diferente, no seu conteúdo, das outras obras do autor. Essas outras obras (1) impuseram-se pelo seu rigor científico e por uma forte preocupação didáctica, e por isso se tornaram obras amplamente utilizadas no ensino universitário. A presente obra confirma e em certo sentido reforça essas qualidades do autor. 
A Criação é uma tentativa de "descrição da natureza e da origem do universo, mas não se trata de mais um livro sobre astronomia ou partículas elementares". O objectivo central do autor consiste em mostrar que por detrás da complexidade aparente do universo se esconde a extrema simplicidade: "... o caminho para o entendimento consiste em eliminar as aparências de forma a pôr a nu a essência. Essa essência é sempre de uma extrema simplicidade". Ao reduzir a complexidade à simplicidade extrema, o autor elimina o Criador como personagem da cena da Criação; na falta de papel para desempenhar, o Criador não pode actuar e transforma-se num mito.

A obra apresenta aspectos muito interessantes no domínio da explicação do mundo físico como por exemplo a explicação da dimensionalidade do espaço-tempo e a explicação de porquê não podemos ver (mas podemos ouvir) para além das esquinas... Estes e outros aspectos fazem do livro uma leitura recomendável para estudantes de ciências de nível universitário, e também para um público mais vasto de posse de uma formação científica elementar.

Peter Atkins não teme a incursão frequente em comentários de natureza especulativa: "Podemos agora reunir estas ideias e deixar a imaginação pairar sobre esta meia eternidade. Começaremos antes do começo, permitiremos a especulação sem limites e prosseguiremos o voo do universo para além do seu futuro". Esta metodologia é extremamente fecunda na medida em que permite ao leitor libertar-se das amarras intelectuais em que determinado tipo de discurso científico invariavelmente o coloca. Para além disso essas "especulaçðes" são credíveis na medida em que são apoiadas por referências apropriadas e tratadas com as necessárias cautelas.

Outro aspecto que importa sublinhar é o carácter conscientemente reducionista da obra: "Este é um ensaio de reducionismo extremo e de racionalismo militante" ou, noutra passagem, "a tendência da energia para o caos transforma-se em amor ou em guerra através da mediação de reacç̃̃es químicas"'. Este carácter reducionista, que poderá constituir razão de sobra para uma investida destrutiva por parte de certos "epistemólogos", é para mim um dos aspectos mais sedutores desta obra de Peter Atkins. Ela é uma boa demonstração de que o reducionismo não é em si um bicho mau a abater do ponto de vista epistemológico. Com efeito, só em casos muito particulares é que as diferentes abordagens reducionistas são contraditórias ou incompativeis. Quem poderá hoje negar a importância da obra de Claude Lévi-Strauss para a antropologia pelo facto de ser estruturalista, ou da de Malinowski ou Robert Merton no campo da sociologia por serem funcionalistas, ou da obra filosófica de Husserl por ser fenomenologista? É certo que a realidade fisica, social ou individual é complexa e que a sua análise exige a consideração dos seus diferentes níveis e da sua articulação. Mas também é certo que o conhecimento global é uma utopia, uma meta a atingir, e que as diferentes abordagens "reducionistas" abrem geralmente perspectivas de conhecimento, evidenciam relaçðes e oferecem explicaçð̃es que em princípio se completam. Não se pretende com isto defender um ecletismo epistemológico, mas sim uma certa forma de pragmatismo: são as interrogaçð̄es bem formuladas que devem determinar os meios epistemológicos e metodológicos a utilizar para produzir respostas pertinentes. Neste contexto $A$ Criação é um livro exemplar. Viva o reducionismo!
Entretanto, a metodologia reducionista revela as suas fraquezas, por exemplo, à medida que o texto se desenvolve na procura do "extremamente simples". Tentemos ilustrar. Para compreender a criação de qualquer coisa a partir do nada, o autor sugere que pensemos no processo inverso da colisão matéria-antimatéria: "A colisão entre uma partícula e uma anti-partícula conduz a essencialmente nada - uma gota de energia". Não estou certo de que o argumento seja convincente para toda a gente. Quando há colisão entre uma partícula e uma anti-partícula, a aniquilação da massa implica o aparecimento de radiação (a gota de energia). Mas essa radiação é o equivalente da massa aniquilada e não há aparentemente razão para considerar que a energia está mais próxima da categoria de "essencialmente nada" do que a massa de que proveio. Poderiam citar-se outros exemplos que parecem todos remeter para limitaçōes próprias da linguagem (e do intelecto de que ela é um reflexo) na exploração desta problemática tão fugidia como é a da Criação. É aliás interessante notar que nestes domínios dificeis a linguagem do autor se modifica, de uma forma claramente voluntária, para assumir um estilo mais afirmativo que demonstrativo, fazendo por vezes lembrar o estilo dos textos bíblicos: "No princípio há o começo. No começo não havia nada. O vazio absoluto e não apenas o espaço vazio. Não havia espaço; nem havia tempo porque isso era antes. do tempo. $\mathrm{O}$ universo era destituido de forma e vazio".

Se a metodologia reducionista se defronta com dificuldades na fronteira da "simplicidade derradeira", algo de semelhante se verifica na fronteira oposta, a da complexidade, a da análise do biológico, do humano e do social. Neste domínio o reducionismo conduz o autor a uma posição que não é nova, que foi claramente formulada por Francis Crick: "o objectivo último das tendências modernas da'biologia é de facto o de explicar toda a biologia em termos de física e de quimica" $\left({ }^{2}\right)$. Também neste domínio o autor recorre a "extravagâncias"' de linguagem que evitam a queda do discurso no cientismo estreito: "É inegável (mas não necessariamente previsível) que uma vez que as moléculas se encontrem face à possibilidade de se reproduzir elas unir-se-ão, aqui ou ali (aí onde isso acontecer), em combinaçð̃es que assumirão a forma e terão as funçð̄es dos homens e que esses homens serão um dia encontrados a deambular na natureza. A sua função especial, mas não significante, consiste em serem capazes de agir como comentadores sobre a natureza, conteúdo, estrutura e origem do universo e, secundariamente, em poderem imaginar e retirar prazer de fantasias comunicáveis".

Esta obra de Peter Atkins tem uma frescura que faz dela como que um poema em prosa que desenvolve um naturalismo visionário. E tem o grande mérito de proporcionar, através de múltiplas consideraçðes e especulações interessantes, um florescer de pensamentos fecundos e excitantes.

\section{REFERENCIAS:}

[1] a) P. W. Atkins, Quanta: a handhook of concepts, Clarendon Press, Oxford (1974); b) P. W. Atkins, Molecular Quantum Mechamics, Clarendon Press (1970); c) P. W. Atkins, Physical Chemistry, Oxford University Press (1978); d) P. W. Atkins, The Second law, Freeman (1983).

[2] Francis Crick, Of Molecules and Men, University of Washington Press, Seattle (1966).

J. J. Moura Ramos

Departamento de Engenharia Química, IST 